\title{
ANALISIS PENDAPATAN USAHA GULA AREN PADA MASYARAKAT YANG TINGGAL DI DALAM DAN DI SEKITAR HUTAN
}

\author{
Income Analysis of Palm Sugar for Community who Living in and around Forest \\ Makkarennu $^{1 凶}$, Muh. Fikri Rum ${ }^{1}$, Ridwan $^{1}$ \\ 1 Fakultas Kehutanan, Universitas Hasanuddin, Jl. Perintis Kemerdekaan Km.10 Tamalanrea Makassar \\ ${ }^{\otimes}$ corresponding author: makkarennu@unhas.ac.id
}

\begin{abstract}
Palm sugar as one of product of Non-Timber Forest Products (NTFPs) which contributes to communities living in and around forests. However, the use and processing of products is still tradistional managed so as to produce results that have not been maximized. This study aims to analyses the income of palm sugar product for farmer groups who living in and around forest. The location of the study was in forest farmer groups in Labuaja Village, Cenrana Sub-District, Maros Regency, South Sulawesi. Sampling was carried out on each farmer group consisting of 10 people in three farmer groups with the number of respondents as many as 30 people conducted by simple random sampling. Data analysis was carried out through qualitative descriptive analysis and quantitative analysis. The results showed that the income of each farmer palm sugar per year was $\mathrm{Rp} .9,562,012$.
\end{abstract}

Key words: forest farmer group; fixed cost; income analysis; palm sugar; variabel cost

\section{A. PENDAHULUAN}

Hutan mempunyai berbagai jenis manfaat yang dapat diusahakan dan dinikmati oleh masyarakat baik yang berwujud nyata (tangible benefits) maupun yang tak berwujud nyata (intangible benefits) (Hani, 2009). Namun pada umumnya, nilai hutan hanya didasarkan pada nilai kayu dari tegakan yang ada (tangible value), potensi lain yang terkandung di dalam hutan seperti hasil hutan bukan kayu (HHBK) seringkali diabaikan. Padahal peran HHBK tidak kalah pentingnya sebagai salah satu sumber pendapatan masyarakat yang berada di sekitar kawasan hutan.

Peran hasil hutan bukan kayu tidak hanya dari segi ekologis, tetapi juga pada aspek ekonomis dan sosial budaya. Dari aspek ekonomis, hasil hutan bukan kayu dapat menjadi salah satu sumber penghasilan bagi masyarakat maupun pemerintah. Sedangkan dari aspek sosial budaya, masyarakat ikut dilibatkan dalam pemanfaatan dan pengolahan hasil hutan bukan kayu (Salaka, dkk. 2012).

Produk hasil hutan bukan kayu merupakan salah satu sumber daya hutan yang terkait langsung dengan masyarakat sekitar hutan. Hasil hutan bukan kayu dapat memberikan atau meningkatkan usaha dan pendapatan masyarakat sekitar hutan. Salah satunya adalah aren, Aren (Arenga Pinnata Merr) yang merupakan salah satu komoditas yang berpotensi untuk dikembangkan disamping dapat memenuhi kebutuhan konsumsi dalam negeri juga sebagai sumber devisa bagi negara termasuk membantu pemerintah dalam penyerapan tenaga kerja (Rura dkk, 2014).

Aren sebagai salah satu sumber pendapatan masyarakat yang bermukim di sekitar kawasan hutan telah dimanfaatkan secara turun temurun. Masyarakat memanfaatkan komoditi ini untuk membuat gula aren dan dijadikan sebagai salah satu sumber pendapatan. Namun demikian masyarakat belum mengusahakannnya sebagai salah satu unit usaha. Mereka hanya memanfaatkan usaha ini sebagai suatu subsiistem untuk memenuhi kebutuhan sehari hari. Penelitian ini dilakukan untuk menganalisis pendapatan yang diterima oleh masyarakat khusunya kelompok tani yang bermukin di sekitar kawasan hutan.

\section{B. METODE PENELITIAN}

Penelitian ini dilaksanakan di Desa Labuaja Kecamatan Cenrana Kabupaten Maros. Populasi dalam penelitian ini adalah seluruh petani yang melakukan usaha tani gula aren di Desa Labuaja Kecamatan Cenrana Kabupaten Maros berjumlah 89 orang dimana populasi tersebut terbagi ke dalam 3 kelompok tani yaitu, Bulu Tanete 28 orang, Tunas Muda 31 orang, dan Bukit Harapan 30 orang. Pengambilan sampel dilakukan pada setiap kelompok tani yang berjumlah 10 orang. Dengan demikian sampel dalam penelitian ini seluruhnya 
berjumlah 30 orang. yang dilakukan dengan metode acak sederhana (Simple Random Sampling).

Tabel 1. Total Biaya Tetap pada Analisis Pendapatan Gula Aren di Desa Labuaja Kecamatan Kecamatan Cenrana Kabupaten Maros

\begin{tabular}{|c|c|c|c|c|}
\hline \multirow[b]{2}{*}{$\begin{array}{c}\text { Nomor } \\
\text { Responden }\end{array}$} & \multicolumn{3}{|c|}{ Biaya Tetap ( Rp. / tahun ) } & \multirow[b]{2}{*}{$\begin{array}{c}\text { Total Biaya } \\
\text { Tetap } \\
\text { (Rp.) }\end{array}$} \\
\hline & $\begin{array}{l}\text { Total Biaya } \\
\text { Peralatan } \\
\text { (Rp.) }\end{array}$ & $\begin{array}{c}\text { Total Biaya } \\
\text { Penyusutan } \\
\text { Alat } \\
\text { (Rp.) }\end{array}$ & $\begin{array}{c}\text { Total } \\
\text { Biaya } \\
\text { Lainnya ( } \\
\text { Rp.) } \\
\end{array}$ & \\
\hline 1. & 1.000 .000 & 180.000 & 200.000 & 1.380 .000 \\
\hline 2. & 950.000 & 167.500 & 312.000 & 1.429 .500 \\
\hline 3. & 1.250 .000 & 226.875 & 274.000 & 1.750 .875 \\
\hline 4. & 1.000 .000 & 174.375 & 188.000 & 1.362 .375 \\
\hline 5. & 1.000 .000 & 180.000 & 344.000 & 1.524 .000 \\
\hline 6. & 1.150 .000 & 207.500 & 188.000 & 1.545 .500 \\
\hline 7. & 950.000 & 167.500 & 200.000 & 1.317 .500 \\
\hline 8. & 1.050 .000 & 186.875 & 312.000 & 1.548 .875 \\
\hline 9. & 1.150 .000 & 207.500 & 200.000 & 1.557 .500 \\
\hline 10. & 950.000 & 167.500 & 200.000 & 1.317 .500 \\
\hline 11. & 1.000 .000 & 180.000 & 200.000 & 1.380 .000 \\
\hline 12. & 950.000 & 167.500 & 332.000 & 1.449 .500 \\
\hline 13. & 1.250 .000 & 226.875 & 250.000 & 1.726 .875 \\
\hline 14. & 950.000 & 167.500 & 188.000 & 1.305 .500 \\
\hline 15. & 1.200 .000 & 214.375 & 344.000 & 1.758 .375 \\
\hline 16. & 1.200 .000 & 220.000 & 238.000 & 1.658 .000 \\
\hline 17. & 950.000 & 167.500 & 188.000 & 1.305 .500 \\
\hline 18. & 950.000 & 167.500 & 238.000 & 1.355 .500 \\
\hline 19. & 1.150 .000 & 207.500 & 312.000 & 1.669 .500 \\
\hline 20. & 950.000 & 167.500 & 188.000 & 1.305 .500 \\
\hline 21. & 950.000 & 167.500 & 238.000 & 1.355 .500 \\
\hline 22. & 1.150 .000 & 207.500 & 312.000 & 1.669 .500 \\
\hline 23. & 950.000 & 167.500 & 238.000 & 1.355 .500 \\
\hline 24. & 950.000 & 167.500 & 200.000 & 1.317 .500 \\
\hline 25. & 950.000 & 167.500 & 332.000 & 1.449 .500 \\
\hline 26. & 1.200 .000 & 214.375 & 208.000 & 1.622 .375 \\
\hline 27. & 1.000 .000 & 174.375 & 188.000 & 1.362 .375 \\
\hline 28. & 1.000 .000 & 180.000 & 200.000 & 1.380 .000 \\
\hline 29. & 1.200 .000 & 220.000 & 220.000 & 1.640 .000 \\
\hline 30. & 950.000 & 167.500 & 262.000 & 1.379 .500 \\
\hline Jumlah & 31.300 .000 & $5.585 . .625$ & 7.294 .000 & 44.179 .625 \\
\hline Rata-rata & 1.043 .333 & $186.187,50$ & 243.133 & 1.472 .654 \\
\hline
\end{tabular}

Data yang diperlukan dalam penelitian ini yaitu data primer dan sekunder. Data primer diperoleh melalui observasi dan wawancara dengan pihak-pihak yang mengetahui tentang produksi nira, pengeluaran biaya-biaya, dan pemasaran gula aren. Wawancara dilakukan dengan responden yang tergabung dalam kelompok tani gula aren di Dusun Pattiro, Desa Labuaja
Kabupaten Maros. Data sekunder diperoleh secara tidak langsung dan melalui literatur kepustakaan dan juga internet yang ada hubungannya dengan penelitian ini.

\section{Analisis Data}

Data dan informasi yang diperoleh dari hasil penelitian akan ditabulasi sesuai dengan tujuan penelitian. Data tersebut kemudian dianalisis dengan menggunakan analisis deskriptif kualitatif dan analisis deskriptif kuantitatif. Analisis deskriptif kualitatif merupakan metode untuk menyelidiki obyek yang tidak dapat diukur dengan angka-angka atau pun ukuran lain yang bersifat eksak (Sugiyono, 2013). Sedangkan analisis deskriptif kuantitatif merupakan metode yang bertujuan menjelaskan fenomena yang ada dengan menggunakan angka-angka untuk menggambarkan karakteristik individu atau kelompok (Rahim dkk, 2010)

Pendapatan petani gula aren dihitung dengan menggunakan rumus sebagai berikut :

I=TR-TC

Di mana, I adalah Pendapatan usaha tani aren / (Rp/ tahun), TR adalah Total Penerimaan / (Rp/ tahun), TC adalah Total Biaya / ( Rp/tahun)

\section{HASIL DAN PEMBAHASAN}

Bahan baku pengolahan gula aren berasal dari nira aren yang dimiliki oleh setiap petani, Kebutuhan air nira setiap petani berbeda-beda tergantung dari banyaknya pohon yang dimiliki. Adapun nira aren yang disadap oleh petani di Desa Labuaja Kecamatan Cenrana Kabupaten Maros dilakukan 2 kali sehari yakni pagi dan sore hari. Sedangkan nira yang diperoleh untuk satu pohon aren berada pada kisaran 8 s/d 10 liter / hari tergantung dari perlakuan yang dilakukan pada saat selesai penyadapan. Pengambilan nira yang dilakukan oleh petani lebih dari satu pohon / hari sehingga rata-rata nira aren yang diperoleh yakni $20 \mathrm{~s} / \mathrm{d} 30$ liter/ hari, dengan perbandingan $5 \mathrm{~s} / \mathrm{d} 6$ liter nira menghasilkan $1 \mathrm{~kg}$ gula aren.

Gula aren dibuat dari hasil penyadapan nira dari pohon aren, proses penyadapan ini biasanya memakan waktu sekitar 24 jam, ditampung dalam sebuah wadah bambu. Setelah penyadapan dilakukan proses penampungan dari hasil penyadapan dari beberapa pohon aren, dengan menggunakan ember. Selanjutnya proses penyaringan dan perebusan, air nira yang sudah terkumpul disaring untuk memisahkan kotoran, kemudian dilakukan perebusan berkisar antara 3-4 jam. Proses mencetak gula merah yang masih berupa cairan kental dituang dengan menggunakan batok kelapa. Proses penuangan adonan ini pun harus cepat, karena jika tidak, akan mengeras dan tidak bisa dicetak. Setelah proses pencetakan selesai dilakukan proses pendinginan sekitar 10-15 menit hingga gula merah sudah cukup mengeras 
dan bisa dilepas dari cetakan. Cetakan-cetakan batok kelapa ini bukan sekali pakai melainkan dipakai berulang-

Tabel 2. Biaya Variabel pada Analisis PendapatanPetani Gula Aren di Desa Labuaja Kecamatan Cenrana Kabupaten Maros.

\begin{tabular}{|c|c|c|c|c|c|c|c|}
\hline \multirow{3}{*}{$\begin{array}{c}\text { Nomor } \\
\text { Responden }\end{array}$} & \multicolumn{6}{|c|}{ Biaya Variabel ( Rp / tahun ) } & \multirow{3}{*}{$\begin{array}{c}\text { Total } \\
\text { Biaya } \\
\text { (Rp/thn ) }\end{array}$} \\
\hline & \multicolumn{3}{|c|}{ Kemiri } & \multicolumn{3}{|c|}{ Kayu Bakar } & \\
\hline & $\begin{array}{c}\text { Jumlah } \\
\text { (Ltr) }\end{array}$ & $\begin{array}{l}\text { Harga Satuan } \\
\text { (Rp.) }\end{array}$ & $\begin{array}{l}\text { Nilai } \\
\text { (Rp.) }\end{array}$ & $\begin{array}{c}\text { Jumlah } \\
\text { (Batang ) }\end{array}$ & $\begin{array}{l}\text { Harga Satuan } \\
\text { (Rp.) }\end{array}$ & $\begin{array}{l}\text { Nilai } \\
\text { (Rp.) }\end{array}$ & \\
\hline 1. & 6 & 20.000 & 120.000 & 20 & 5.000 & 100.000 & 220.000 \\
\hline 2. & 6 & 20.000 & 120.000 & 20 & 5.000 & 100.000 & 220.000 \\
\hline 3. & 8 & 20.000 & 160.000 & 25 & 5.000 & 125.000 & 285.000 \\
\hline 4. & 5 & 20.000 & 100.000 & 15 & 5.000 & 75.000 & 175.000 \\
\hline 5. & 8 & 20.000 & 160.000 & 25 & 5.000 & 125.000 & 285.000 \\
\hline 6. & 6 & 20.000 & 120.000 & 20 & 5.000 & 100.000 & 220.000 \\
\hline 7. & 6 & 20.000 & 120.000 & 20 & 5.000 & 100.000 & 220.000 \\
\hline 8. & 8 & 20.000 & 160.000 & 25 & 5.000 & 125.000 & 285.000 \\
\hline 9. & 6 & 20.000 & 120.000 & 20 & 5.000 & 100.000 & 220.000 \\
\hline 10 & 8 & 20.000 & 160.000 & 25 & 5.000 & 125.000 & 285.000 \\
\hline 11. & 6 & 20.000 & 120.000 & 20 & 5.000 & 100.000 & 220.000 \\
\hline 12. & 6 & 20.000 & 120.000 & 20 & 5.000 & 100.000 & 220.000 \\
\hline 13. & 6 & 20.000 & 120.000 & 20 & 5.000 & 100.000 & 220.000 \\
\hline 14. & 6 & 20.000 & 120.000 & 20 & 5.000 & 100.000 & 220.000 \\
\hline 15. & 8 & 20.000 & 160.000 & 25 & 5.000 & 125.000 & 285.000 \\
\hline 16. & 8 & 20.000 & 160.000 & 25 & 5.000 & 125.000 & 285.000 \\
\hline 17. & 5 & 20.000 & 100.000 & 15 & 5.000 & 75.000 & 175.000 \\
\hline 18. & 5 & 20.000 & 100.000 & 15 & 5.000 & 75.000 & 175.000 \\
\hline 19. & 6 & 20.000 & 120.000 & 20 & 5.000 & 100.000 & 220.000 \\
\hline 20 & 5 & 20.000 & 100.000 & 15 & 5.000 & 75.000 & 175.000 \\
\hline 21. & 6 & 20.000 & 120.000 & 20 & 5.000 & 100.000 & 220.000 \\
\hline 22. & 6 & 20.000 & 120.000 & 20 & 5.000 & 100.000 & 220.000 \\
\hline 23. & 5 & 20.000 & 100.000 & 15 & 5.000 & 75.000 & 175.000 \\
\hline 24. & 8 & 20.000 & 160.000 & 25 & 5.000 & 125.000 & 285.000 \\
\hline 25. & 8 & 20.000 & 160.000 & 25 & 5.000 & 125.000 & 285.000 \\
\hline 26. & 5 & 20.000 & 100.000 & 15 & 5.000 & 75.000 & 175.000 \\
\hline 27. & 5 & 20.000 & 100.000 & 15 & 5.000 & 75.000 & 175.000 \\
\hline 28. & 6 & 20.000 & 120.000 & 20 & 5.000 & 100.000 & 220.000 \\
\hline 29. & 6 & 20.000 & 120.000 & 20 & 5.000 & 100.000 & 220.000 \\
\hline 30 & 5 & 20.000 & 100.000 & 15 & 5.000 & 75.000 & 175.000 \\
\hline Jumlah & 188 & 20.000 & 3.760 .000 & 600 & 5.000 & 3.000 .000 & 6.760 .000 \\
\hline Rata - rata & - & - & 125.333 & 20 & - & 100.000 & 225.333 \\
\hline
\end{tabular}

ulang sehingga harus dicuci setelah dipakai mencetak dan sebelum dipakai pada pencetakan berikutnya. Gula merah yang sudah dilepas dari cetakan tidak langsung dikemas, tapi diangin-anginkan dulu agar lebih kering. Proses yang terakhir yaitu proses pengemasan, gula aren yang telah mengeras dan dingin harus dikemas di dalam wadah yang tertutup sehingga terhindar dari uap air.

\section{Analisis Pendapatan}

\section{Biaya Tetap (Fixed Cost)}

Biaya tetap (fixed cost) adalah jenis biaya yang selama kisaran waktu operasi tertentu atau tingkat kapasitas produksi tertentu selalu tetap jumlahnya atau tidak berubah walaupun produksi volume berubah (Jumingan, 2011). Jumlah produksi akan berbanding terbalik dengan biaya per unit, sehingga semakin tinggi jumlah produksi maka biaya per unit semakin menurun. Adapun biaya tetap yang dikeluarkan pada usaha gula aren adalah biaya peralatan yang terdiri atas wajan, kapak dan parang, sedangkan biaya penyusutan dan biaya tetap lainnya terdiri atas bambu, tali rapiah, tenaga kerja dan biaya sewa lahan. Biaya tetap untuk peralatan dan penyusutannya dapat dilihat pada Tabel 1 .

Dari tabel di atas menunjukkan bahwa komponen biaya tetap yang dihitung yakni total biaya harga peralatan, total biaya penyusutan alat dan total biaya tetap lainnya yakni sebanyak Rp. 44.179.625. dengan rata-rata Rp. 1.472.654. 
Tabel 3. Biaya Total Pengeluaran pada Analisis Pendapatan Gula Aren di Desa Labuaja Kecamatan Cenrana Kabupaten Maros

\begin{tabular}{cccc}
\hline $\begin{array}{c}\text { Nomor } \\
\text { Responden }\end{array}$ & $\begin{array}{c}\text { Biaya Tetap } \\
(\text { Rp.) }\end{array}$ & $\begin{array}{c}\text { Biaya } \\
\text { Variabel } \\
\text { (Rp.) }\end{array}$ & $\begin{array}{c}\text { Total Biaya } \\
\text { Pengeluaran } \\
\text { (Rp.) }\end{array}$ \\
\hline 1 & 1.380 .000 & 220.000 & 1.600 .000 \\
2 & 1.429 .500 & 220.000 & 1.649 .500 \\
3 & 1.750 .875 & 285.000 & 2.035 .875 \\
4 & 1.362 .375 & 175.000 & 1.537 .375 \\
5 & 1.524 .000 & 285.000 & 1.809 .000 \\
6 & 1.545 .500 & 220.000 & 1.765 .500 \\
7 & 1.317 .500 & 220.000 & 1.537 .500 \\
8 & 1.548 .875 & 285.000 & 1.833 .875 \\
9 & 1.557 .500 & 220.000 & 1.777 .500 \\
10 & 1.317 .500 & 285.000 & 1.602 .500 \\
11 & 1.380 .000 & 220.000 & 1.600 .000 \\
12 & 1.449 .500 & 220.000 & 1.669 .500 \\
13 & 1.726 .875 & 220.000 & 1.946 .875 \\
14 & 1.305 .500 & 220.000 & 1.525 .500 \\
15 & 1.758 .375 & 285.000 & 2.043 .375 \\
16 & 1.658 .000 & 285.000 & 1.943 .000 \\
17 & 1.305 .500 & 175.000 & 1.480 .500 \\
18 & 1.355 .500 & 175.000 & 1.530 .500 \\
19 & 1.669 .500 & 220.000 & 1.889 .500 \\
20 & 1.305 .500 & 175.000 & 1.480 .500 \\
21 & 1.355 .500 & 220.000 & 1.575 .500 \\
22 & 1.669 .500 & 220.000 & 1.889 .500 \\
23 & 1.355 .500 & 175.000 & 1.530 .500 \\
24 & 1.317 .500 & 285.000 & 1.602 .500 \\
25 & 1.449 .500 & 285.000 & 1.734 .500 \\
26 & 1.622 .375 & 175.000 & 1.797 .375 \\
27 & 1.362 .375 & 175.000 & 1.537 .375 \\
28 & 1.380 .000 & 220.000 & 1.600 .000 \\
29 & 1.640 .000 & 220.000 & 1.860 .000 \\
30 & 1.379 .500 & 175.000 & 1.554 .500 \\
\hline Jumlah & 44.179 .625 & 6.760 .000 & 50.939 .625 \\
\hline Rata-rata & 1.472 .654 & 225.333 & 1.697 .987 \\
\hline & & & \\
\hline
\end{tabular}

\section{Biaya Variabel (Variable Cost)}

Biaya variabel adalah besarnya biaya yang tergantung pada banyaknya produk dan jasa yang dihasilkan. Komponen biaya yang diperhitungkan dalam penelitian ini meliputi kemiri dan kayu bakar. Kemiri ini digunakan untuk mencampur nira pada saat proses pemasakan berlangsung. Penambahan kemiri ini dimaksudkan untuk mempercepat proses pengentalan gula aren yang dihasilkan. Dengan demikian maka biayabiaya yang dikeluarkan dalam kegiatan ini dapat diketahui. Untuk jelasnya dapat dilihat pada Tabel 2.

Tabel 2 menunjukkan pemakaian kemiri dan kayu bakar merupakan hal yang sangat penting dalam pengolahan gula aren. Adapun biaya variabel yang dikeluarkan yakni sebanyak Rp. 6.760 .000 dengan ratarata $\mathrm{Rp} .225 .333$.
Tabel 4. Pendapatan Usaha Gula Aren

\begin{tabular}{|c|c|c|c|}
\hline $\begin{array}{c}\text { Nomor } \\
\text { Responden }\end{array}$ & $\begin{array}{l}\text { Penerimaan } \\
\text { (Rp/thn ) }\end{array}$ & $\begin{array}{l}\text { Total Biaya } \\
\text { Pengeluaran } \\
\text { (Rp/thn ) }\end{array}$ & $\begin{array}{c}\text { Pendapatan } \\
\text { (Rp/thn ) }\end{array}$ \\
\hline 1 & 9.600 .000 & 1.600 .000 & 8.000 .000 \\
\hline 2 & 16.800 .000 & 1.649 .500 & 15.150 .500 \\
\hline 3 & 18.000 .000 & 2.035 .875 & 15.964 .125 \\
\hline 4 & 10.200 .000 & 1.537 .375 & 8.662 .625 \\
\hline 5 & 18.000 .000 & 1.809 .000 & 16.191 .000 \\
\hline 6 & 9.000 .000 & 1.765 .500 & 7.234 .500 \\
\hline 7 & 9.000 .000 & 1.537 .500 & 7.462 .500 \\
\hline 8 & 16.800 .000 & 1.833 .875 & 14.966 .125 \\
\hline 9 & 9.600 .000 & 1.777 .500 & 7.822 .500 \\
\hline 10 & 9.600 .000 & 1.602 .500 & 7.997 .500 \\
\hline 11 & 7.200 .000 & 1.600 .000 & 5.600 .000 \\
\hline 12 & 16.800 .000 & 1.669 .500 & 15.130 .500 \\
\hline 13 & 7.200 .000 & 1.946 .875 & 5.253 .125 \\
\hline 14 & 7.200 .000 & 1.525 .500 & 5.674 .500 \\
\hline 15 & 16.800 .000 & 2.043.375 & 14.756 .625 \\
\hline 16 & 8.400 .000 & 1.943 .000 & 6.457 .000 \\
\hline 17 & 7.200 .000 & 1.480 .500 & 5.719 .500 \\
\hline 18 & 8.400 .000 & 1.530 .500 & 6.869 .500 \\
\hline 19 & 16.800 .000 & 1.889 .500 & 14.910 .500 \\
\hline 20 & 9.600 .000 & 1.480 .500 & 8.119 .500 \\
\hline 21 & 8.400 .000 & 1.575 .500 & 6.824 .500 \\
\hline 22 & 16.800 .000 & 1.889 .500 & 14.910 .500 \\
\hline 23 & 7.200 .000 & 1.530 .500 & 5.669 .500 \\
\hline 24 & 7.200 .000 & 1.602 .500 & 5.597 .500 \\
\hline 25 & 16.800 .000 & 1.734 .500 & 15.065 .500 \\
\hline 26 & 8.400 .000 & 1.797 .375 & 6.602 .625 \\
\hline 27 & 8.400 .000 & 1.537 .375 & 6.862 .625 \\
\hline 28 & 7.200 .000 & 1.600 .000 & 5.600 .000 \\
\hline 29 & 8.400 .000 & 1.860 .000 & 6.540 .000 \\
\hline 30 & 16.800 .000 & 1.554 .500 & 15.245 .500 \\
\hline Jumlah & 337.800 .000 & 50.939 .625 & 286.860 .375 \\
\hline Rata - rata & 11.260 .000 & 1.697 .987 & 9.562 .012 \\
\hline
\end{tabular}

\section{Biaya Total (Total Cost)}

Biaya total adalah biaya-biaya yang terjadi untuk menghasilkan suatu produk jadi yang siap untuk dijual atau biaya total adalah seluruh biaya yang dibebankan dalam melaksanakan kegiatan produksi atau menghasilkan kegiatan lain. Biaya total pengeluaran pada usaha gula aren di Desa ini sebesar Rp. 50.939.625 dengan rata-rata pengeluaran setiap petani sebesar Rp. 1.697.987, untuk jelasnya dapat dilihat pada Tabel 3.

\section{Penerimaan dan Pendapatan Gula Aren}

Pendapatan merupakan hal yang sangat penting karena pendapatan menjadi obyek terhadap kegiatan pengolahan nira aren di Desa Labuaja Kecamatan Cenrana Kabupaten Maros. Pendapatan adalah 
banyaknya uang yang diterima masing-masing responden setelah dikurangi biaya pengeluaran. Pendapat usaha gula aren di Desa Labuaja Kecamatan Cenrana Kabupaten Maros dapat dilihat Tabel 4.

\section{E. KESIMPULAN}

Usaha pengolahan gula aren dengan produk gula batok di Kecamatan Cenrana Kabupaten Maros memberikan pendapatan kepada masyarakat yakni sebesar Rp. 286.860.375 per tahun atau rata-rata pendapatan setiap petani sebesar Rp. 9.562.012 per tahun.

\section{DAFTAR PUSTAKA}

Hani, A. (2009). Pengembangan Tanaman Penghasil Hasil Hutan Bukan Kayu Melalui Perbanyakan Vegetatif. Jurnal Tekno Hutan Tanaman, 2(2) : 83-92.
Jumingan, M.M. (2011). Analisis Laporan Keuangan. Jakarta: Penerbit PT. Bumi Aksara.

Rahim, A., Alam, N., Haryadi \& Santoso, U. (2010). Pengaruh Konsentrasi Pati Aren dan Minyak Sawit Terhadap Sifat Fisik dan Mekanik. di Kecamatan Nokilalaki Kabupaten Sigi, Sulawesi Tengah. Jurnal Agroland, 17(1): 38-46.

Rofik, A., \& Murniati. (2008). Pengaruh perlakuan deo perkulasi dan media perkecambahan untuk meningkatkan viabilitas benih aren (Arenga pinnata (Wurmb) Merr.). Universitas Andalas Sumatera Barat. Jurnal Buletin Agronomi, 36 (1): 33-40.

Rura, Y., Umar, S., \& Alam, A.S. (2014). Analisis Pemasaran Biji Kemiri (Aleurites Mollucana (L.) Willd) di Desa Bakubakulu Kecamatan Palolo Kabupaten Sigi. Jurnal Warta Rimba, 2(2): 8-16. ISSN: 2406-8373

Salaka, F.J., Nugroho, B., \& Nurrochmat, D.R. (2012). Strategi Kebijakan Pemasaran Hasil Hutan Bukan Kayu di Kabupaten Seram Bagian Barat, Maluku. Jurnal Analisis Kebijakan Kehutanan, 9(1): 50-65.

Sugyono. (2013). Metode Kuantitatif/Kualitatif Research \& Development. Bandung: Alfabeta.. 